\title{
Primary Cutaneous Anaplastic Large Cell Lymphoma: A Case Report
}

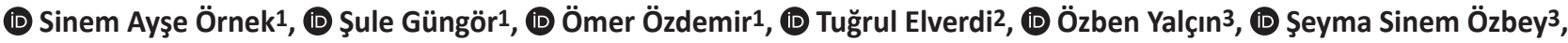 \\ (D) Emek Kocatürk ${ }^{1}$
}

1istanbul Okmeydanı Training and Research Hospital, Clinic of Dermatology, Istanbul, Turkey

2istanbul Okmeydanı Training and Research Hospital, Clinic of Hematology, Istanbul, Turkey

3 istanbul Okmeydanı Training and Research Hospital, Clinic of Pathology, Istanbul, Turkey

\section{Abstract}

Primary cutaneous anaplastic large cell lymphoma (PCALCL) is a rare cutaneous CD30 + T cell lymphoproliferative disorder. PCALCL usually presents as solitary and localized nodules and tumors, or may be multiple and ulcerated. Extracutaneous involvement may occur rarely. Systemic anaplastic large cell lymphoma with secondary cutaneous involvement has a similar clinical appearance to PCALCL, but differs in treatment and prognosis. Thus, systemic evaluation of patients considered as PCALCL is critical. An 82-year-old male patient presented with three progressive lesions on the scalp. The final diagnosis was PCALCL with extracutaneous involvement based upon the involvement of regional lymph nodes, liver and spleen, lack of systemic B symptoms and the results of histopathological and immunophenotypical studies. This case is presented to emphasize the necessity of systemic evaluation in patients considered as PCALCL and to remind how to differentiate PCALCL from systemic lymphomas.

Keywords: Primary cutaneous anaplastic large cell lymphoma, cutaneous lymphoma, CD30 positivity

\section{INTRODUCTION}

Primary cutaneous anaplastic large cell lymphoma (PCALCL) is a rare CD30 + T cell lymphoproliferative disease of the skin (1). PCALCL is clinically seen as one or more ulcerable nodules and tumors (2). Rarely, extracutaneous involvement may occur (3). Cutaneous involvement secondary to systemic anaplastic large cell lymphoma is clinically similar to PCALCL, but treatment and prognosis vary (4). Therefore, it is important to investigate systemic disease in patients with PCALCL. The diagnosis of PCALCL is usually made by clinical findings, histopathological and immunophenotypical examination and the absence of systemic disease (5).

\section{CASE REPORT}

An 82-year-old male patient presented to our clinic with three lesions on the scalp that grew and became a mass. The history revealed that the first lesion had occurred one year ago and had occasional bleeding; the other two had developed in the last 2 months and had no symptoms. Dermatological examination revealed a $3 \times 3 \times 1.5 \mathrm{~cm}$ sized, hard, brown-red-colored nodular lesion with hemorrhagic crust and yellow squama on the right frontoparietal region. Two $1.5 \times 1.5 \times 0.5 \mathrm{~cm}$ sized, brown-redcolored, nodular lesions were observed on bilateral posterior parietal regions (Figures 1, 2). He did not have weight loss, night sweats, decreased appetite, and fever. Histopathological examination revealed a large infiltrate of atypical lymphocytes in the dermis. Immunohistochemically, cells were positive for CD30, CD4, CD3, CD45 RO, MUM1, and negative for CD20, anaplastic lymphoma kinase (ALK), epithelial membrane antigen (EMA), Melan A, S100, BCL6, glial fibrillary acidic protein and Epstein-Barr virus. The KI 67 proliferation index was 90\% (Figures 3-9). Laboratory tests and thoracic computed tomography (CT) evaluating systemic involvement were normal. Abdomen CT examination revealed a $10 \mathrm{~mm}$ hypodense nodule in the left and right lobes of the liver and $1 \mathrm{~mm}$ in the medial spleen. 


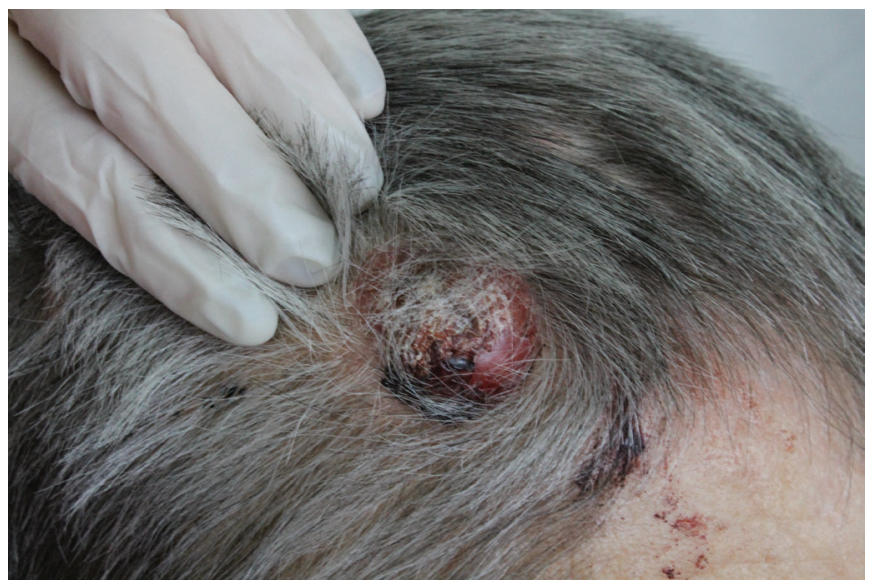

Figure 1. A $3 \times 3 \times 1.5 \mathrm{~cm}$ sized, hard, brown-red nodular lesion with hemorrhagic crust and yellow squama on the right frontoparietal region

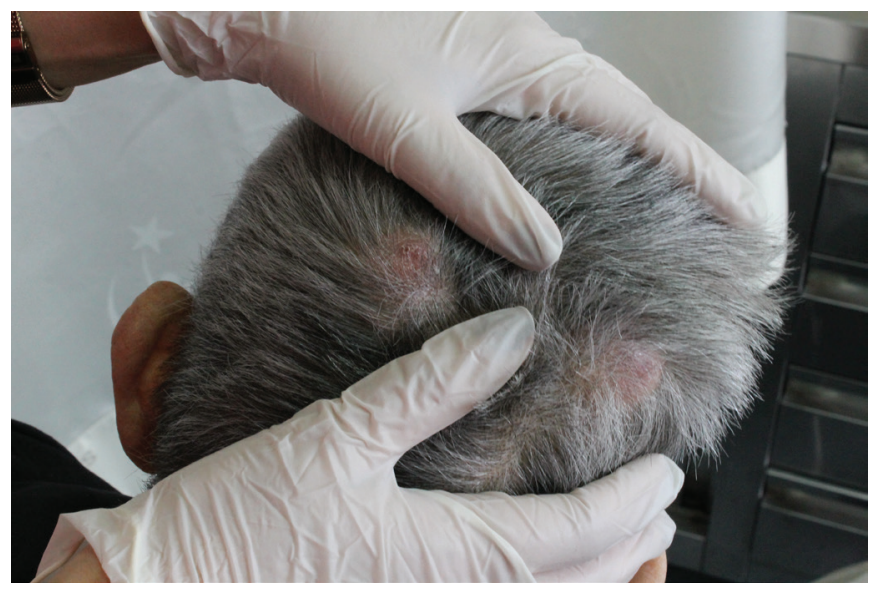

Figure 2. Two $1.5 \times 1.5 \times 0.5 \mathrm{~cm}$ sized, brown-red nodular lesions with a slight squama on the posterior of the bilateral parietal region

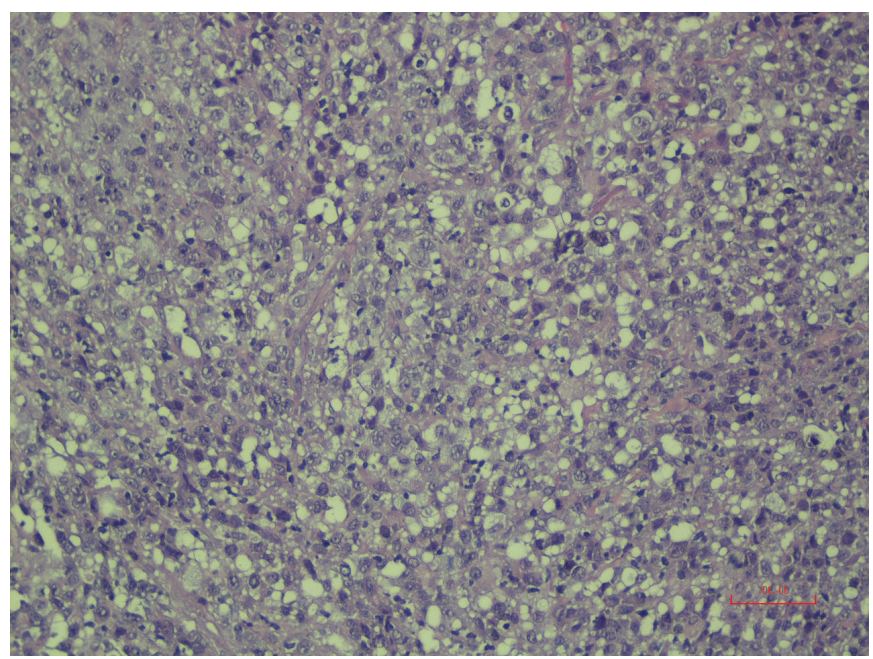

Figure 3. Infiltrate of large atypical lymphocytes in the dermis (hematoxylin and eosin, x100)

Positron emission tomography examination showed increased F-18 fluorodeoxyglucose uptake in localized sites that matched the skin-subcutaneous lesions on the scalp, left posterior cervical

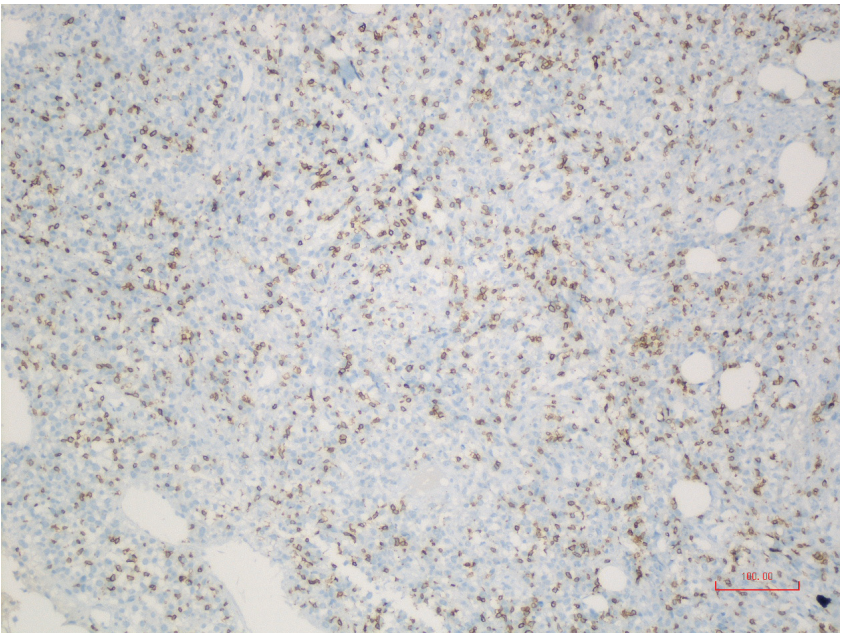

Figure 4. Positive staining with $C D 3$

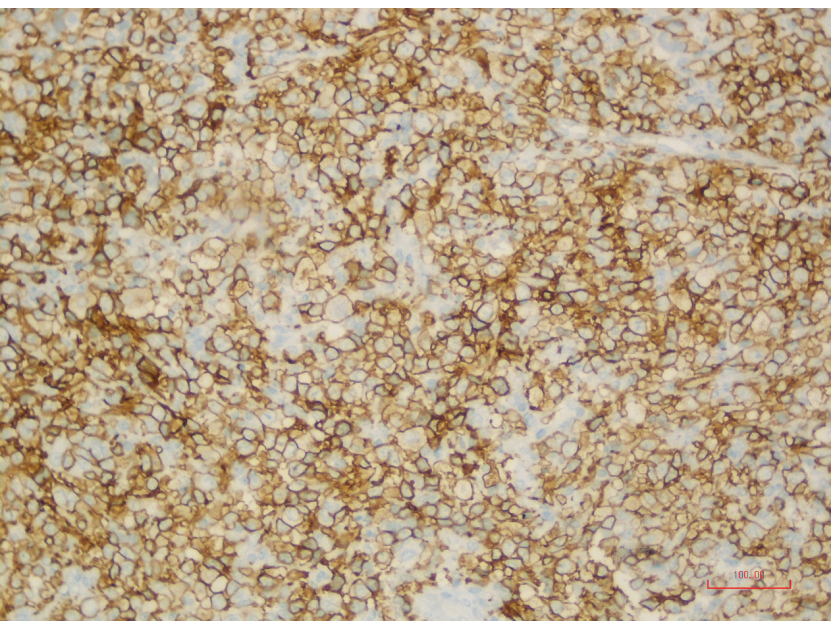

Figure 5. Positive staining with CD30

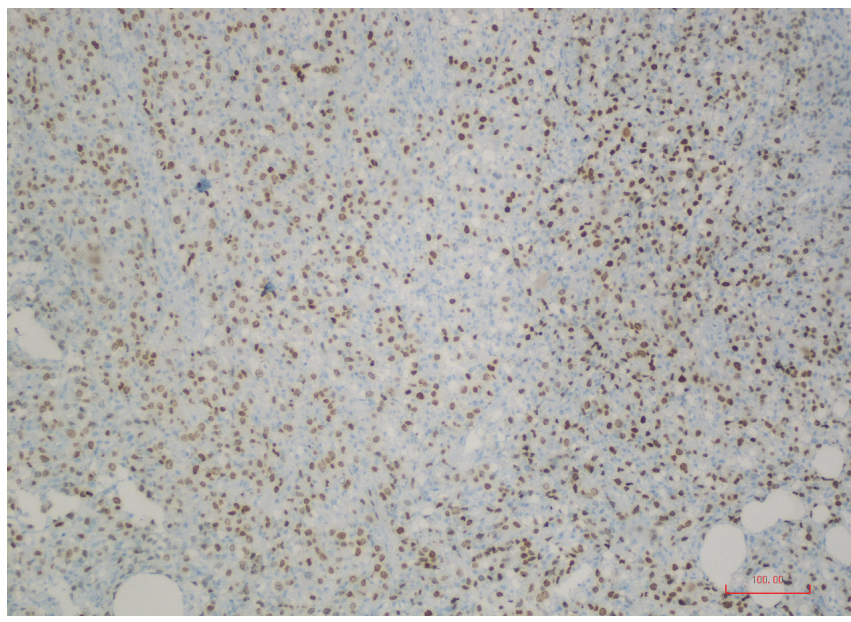

Figure 6. Positive staining with MUM1

lymph nodes in the neck, and in the liver and spleen that matched the hypodense nodules seen on CT. As the lesion was immunohistochemically negative for ALK and EMA, the patient was diagnosed as PCALCL with extracutaneous involvement 


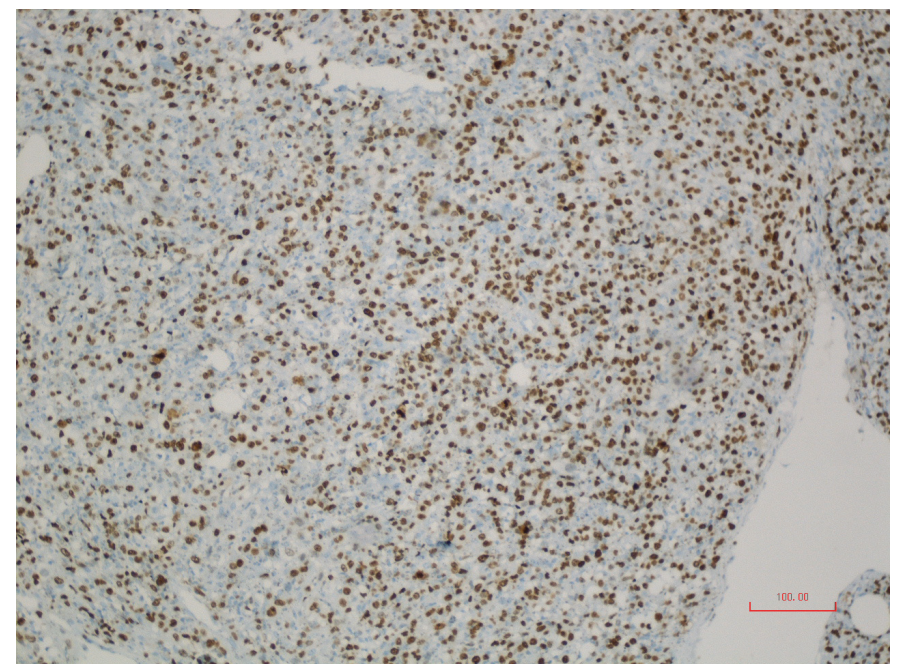

Figure 7. 90\% Ki67 proliferation index

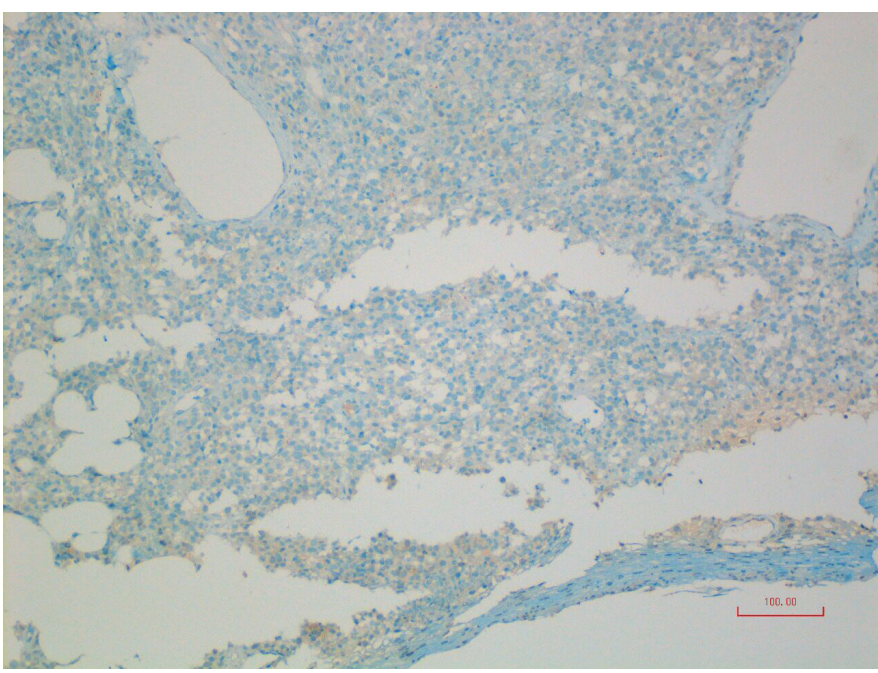

Figure 8. Negative staining with anaplastic lymphoma kinase

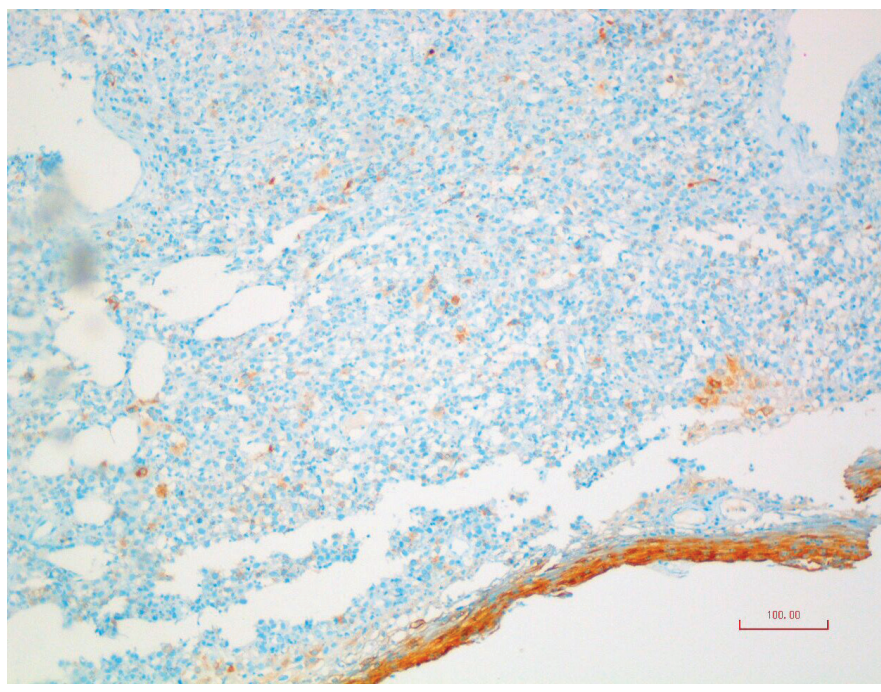

Figure 9. Negative staining with epithelial membrane antigen

\section{DISCUSSION}

Primary cutaneous lymphomas are a heterogeneous group of diseases consisting of extranodal non-Hodgkin's lymphomas that present in the skin. Unlike nodal non-Hodgkin lymphomas, 75\% of primary cutaneous lymphomas are of $\mathrm{T}$ lymphocyte origin and the majority are mycosis fungoides and Sezary syndrome. This is followed by lymphoid papulosis and that present in the skin as CD30 + T cell lymphomas (6). PCALCL accounts for 10\% of all cutaneous $\mathrm{T}$ cell lymphomas. It is usually seen after the $6^{\text {th }}$ decade and is common in men. The most common site of involvement is the head and extremities. Clinically, it is seen as one or more nodules and tumors that can ulcerate. The etiology is unknown. Unlike systemic ALCL, it has a good prognosis and spontaneous regression can be seen (7). Rarely, extracutaneous dissemination may occur and involves regional lymph nodes and viscera (6). The diagnosis of PCALCL is made by clinical findings, histopathological and immunophenotypical examination and imaging methods (5). In histopathological examination, CD4+ T lymphocytes with CD30 + anaplastic morphology form nonepidermotropic diffuse infiltrate in the dermis. Mitosis rate is high. Ulcerated lesions may be accompanied by inflammatory infiltrates of reactive lymphocytes, histiocytes, eosinophils and neutrophils (6). Immunohistochemical studies are important in distinguishing between primary and secondary lesions that are clinically and histopathologically similar. Unlike systemic CD30 + lymphomas, PCALCL is not stained with EMA and ALK immunostaining (8). Imaging techniques are necessary both for staging the disease and for distinguishing between primary and secondary. In order to diagnose PCALCL, it should be shown that there is no systemic involvement (7). In our case, there were regional lymph nodes, liver and spleen involvement as well as skin involvement at the time of diagnosis. It could not be determined that the involvement of lymph nodes and viscera were before or after the cutaneous lesions, since there was no previous examination. However, the patient was diagnosed as PCALCL with extracutaneous involvement due to lack of B symptoms (fever, night sweats, weight loss) which are suggestive of systemic lymphoma and immunohistochemical studies showing negative ALK and EMA staining. Surgical excision and radiotherapy are the treatment options for localized PCALCL cases. In case of extracutaneous involvement, systemic multiple chemotherapy is applied (9). Recent studies have reported cases of complete remission with brentuximab vedotin, an anti-CD30 monoclonal antibody (10). We did not have the opportunity to initiate any treatment because our patient died one month after the diagnosis. 
PCALCL has a better prognosis than systemic lymphomas. Ten-year survival has been reported to be $90 \%$ (8). However, the presence of widespread skin lesions, muscle and deep fascia involvement, the occurrence of lesions in the leg and extracutaneous involvement reduces survival (11-13). In the study of Benner and Willemze (3), 14.8\% of 135 patients with PCALCL showed extracutaneous invasion. It was reported that $70 \%$ of the patients were alive and in remission, $6 \%$ were alive and under treatment, $8.9 \%$ died due to lymphoma and $14 \%$ died due to another cause. In the study of Hapgood et al. (14) $15 \%$ of 47 PCALCL cases showed extracutaneous spread. It was reported that $57 \%$ of the patients were alive and in remission, $13 \%$ were alive and under treatment, 9\% died due to lymphoma and $21 \%$ died due to another cause. In another study by Benner and Willemze (15), 5-year survival rates of patients with and without lymph node and visceral organ involvement were reported as $51 \%$ and $80 \%$, respectively. In conclusion, since treatment and prognosis differ by origin, staging is important in patients with PCALCL and systemic and primary cutaneous lymphoma should be differentiated by clinical findings, imaging methods, histopathological and immunophenotypical examination.

\section{Ethics}

Informed Consent: Writing concept of the patient was received.

Peer-review: Externally peer-reviewed.

\section{Authorship Contributions}

Surgical and Medical Practices: S.A.Ö., S..G., Ö.Ö., T.E., Concept: S.A.Ö., S.G., E.K., Design: S.A.Ö., S.G., Data Collection or Processing: S.A.Ö., Ö.Ö., Ö.Y., S.S.Ö., Analysis or Interpretation: S.A.Ö., S.G., T.E., E.K., Literature Search: S.A.Ö., Writing: S.A.Ö.

Conflict of Interest: No conflict of interest was declared by the authors.

Financial Disclosure: The authors declared that this study received no financial support.

\section{REFERENCES}

1. Swerdlow SH, Campo E, Harris NL, Jaffe ES, Stein H, Thiele J,Vardiman J. WHO classification of tumours of haematopoietic and lymphoid tissue. 4th ed. Lyon: IARC Press; 2008
2. Bekkenk MW, Geelen FA, van Voorst Vader PC, Heule F, Geerts ML van Vloten WA, et al. Primary and secondary cutaneous CD30 (+) lymphoproliferative disorders: a report from the Dutch Cutaneous Lymphoma Group on the long-term follow-up data of 219 patients and guidelines for diagnosis and treatment. Blood 2000;95:3653-61.

3. Benner MF and Willemze R. Applicability and prognostic value of the New TNM Classification System in 135 patients with Primary Cutaneous Anaplastic Large Cell Lymphoma. Arch Dermatol 2009;145:1399-404.

4. Willemze R, Hodak E, Zinzani PL, Specht L, Ladetto M. ESMO Guidelines Working Group. Primary cutaneous lymphomas: ESMO clinical practice guidelines for diagnosis, treatment and follow-up. Ann Oncol 2013;24:14954

5. Brown RA, Fernandez-Pol S, Kim J. Primary cutaneous anaplastic large cell lymphoma. J Cutan Pathol 2017;44:570-7.

6. Willemze R, Jaffe ES, Burg G, Cerroni L, Berti E, Swerdlow SH, et al. WHOEORTC classification for cutaneous lymphomas. Blood 2005;105:3768-85.

7. Rao SD, Ravi R, Govindarajan M. Primary cutaneous CD 30+ anaplastic large cell lymphoma. Indian J Surg 2010;72:283-5.

8. Kempf W, Willemze R, Jaffe ES, Burg G, Kadin ME. CD30+ T-cel lymphoproliferative disorders. In: LeBoit PE, Burg G, Weedon D, Sarasin A, eds. WHO/IARC classification of tumours. Pathology and genetics of skin tumours. Lyon: IARC Press; 2006;179-81.

9. Liu HL, Hoppe RT, Kohler S, Harvell JD, Reddy S, Kim YH. CD30+ cutaneous Iymphoproliferative disorders: the Stanford experience in lymphomatoid papulosis and primary cutaneous anaplastic large cell lymphoma. J Am Acad Dermatol 2003;49:1049-58.

10. Desai A, Telang GH, Olszewski AJ. Remission of primary cutaneous anaplastic large cell lymphoma after a brief course of brentuximab vedotin. Ann Hematol 2013;92:567-8.

11. Sugaya M, Fujita H, Izutsu K, Oshima K, Takazawa Y, Ohmatsu H, et al. Primary cutaneous anaplastic large cell lymphoma with leg involvement: a case report and review of 11 cases. J Dermatol 2011;38:1009-12.

12. Woo DK, Jones CR, Vanoli-Storz MN, Kohler S, Reddy S, Advani R, et al Prognostic factors in primary cutaneous anaplastic large cell lymphoma: characterization of clinical subset with worse outcome. Arch Dermatol 2009;145:667-74.

13. Lee WJ, Moon IJ, Lee SH, Won CH, Chang SE, Choi JH, et al. Cutaneous anaplastic large-cell lymphoma (ALCL): A comparative clinical feature and survival outcome analysis of 52 cases according to primary tumor site. J Am Acad Dermatol 2016;74:1135-43.

14. Hapgood G, Pickles T, Sehn LH, Villa D, Klasa R, Scott DW, et al. Outcome of primary cutaneous anaplastic large cell lymphoma: a 20-year British Columbia Cancer Agency experience. Br J Haematol 2017;176:234-40.

15. Benner MF and Willemze R. Bone marrow examination has limited value in the staging of patients with an anaplastic large cell lymphoma first presenting in the skin. Retrospective analysis of 107 patients. Br J Dermatol 2008;159:1148-51. 